\title{
Heterogeneity of endoscopy negative heartburn: Epidemiology and natural history
}

\author{
Fabio Pace, Valentina Casini, Stefano Pallotta
}

Fabio Pace, Department of Clinical Sciences "L. Sacco" University Hospital, Milan 20157, Italy

Valentina Casini, Stefano Pallotta, Division of Gastroenterology, "L. Sacco" University Hospital, Milan 20157, Italy

Author contributions: Pace F had the idea and wrote the outline of the manuscript; Casini V and Pallotta $\mathrm{S}$ assisted in editorial work.

Correspondence to: Fabio Pace, Professor, Department of Clinical Sciences "L. Sacco" University Hospital, Milan 20157, Italy. fabio.pace@unimi.it

Telephone: +39-2-39042943 Fax: +39-2-39042337

Received: June 5, $2008 \quad$ Revised: August 13, 2008

Accepted: August 20, 2008

Published online: September 14, 2008

\begin{abstract}
It has now become clear that only about $40 \%$ or less of patients with heartburn and/or regurgitation have esophagitis, and that the majority of them lack visible distal esophageal mucosa breaks. These subjects are referred to as non-erosive gastroesophageal reflux disease (NERD) patients. It has been estimated that in the Western world at least one tenth of the general population has at least weekly heartburn. This proportion seems to be lower in Asia, while prevalence is rapidly increasing. Although it would be extremely useful to have prospective information regarding the fate of such patients, the natural history of NERD is largely unknown, and very few studies in the literature have addressed this issue. These studies are for the greater part old, not well conducted, and suffer from methodological drawbacks including ill-defined entry criteria. However, a review of these studies indicates that a consistent minority of NERD patients may develop erosive disease at an approximate rate of about $10 \%$ per year.
\end{abstract}

(c) 2008 The WJG Press. All rights reserved.

Key words: Gastroesophageal reflux disease; Nonerosive gastroesophageal reflux disease; Esophagitis; Proton pump inhibitor

Peer reviewer: Tomohiko Shimatani, Assistant Professor, Department of General Medicine, Hiroshima University Hospital, 1-2-3 Kasumi, Minami-ku, Hiroshima 7348551, Japan

Pace F, Casini V, Pallotta S. Heterogeneity of endoscopy negative heartburn: Epidemiology and natural history. World $J$ Gastroenterol 2008; 14(34): 5233-5236 Available from: URL: http://www.wjgnet.com/1007-9327/14/5233.asp DOI: http:// dx.doi.org/10.3748/wjg.14.5233

\section{INTRODUCTION}

The recently published Montreal Criteria, dealing with a global classification of gastroesophageal reflux disease (GERD), define heartburn as a burning sensation in the retrosternal area (behind the breastbone) (level of agreement $=100 \%$ ), claim gastroesophageal reflux (GER) as the most common cause of heartburn (level of agreement $=100 \%$ ), but admit that heartburn can have a number of non-reflux related causes (level of agreement $98 \%$ ) and that the prevalence of these is unknown ${ }^{[1]}$. Moreover, these criteria state that the typical reflux syndrome can be diagnosed on the basis of the presence of characteristic symptoms, i.e. heartburn and regurgitation, without diagnostic testing (level of agreement $=100 \%$ ). The epidemiology of heartburn shows a clear geographical variation; in North America heartburn occurring at least weekly ranges between $13.2 \%$ and $27 \%$; it is slightly lower in Europe ranging between $7.7 \%$ and $15 \%$, whereas the prevalence remains definitely lower of in Asia $(3.1 \%)^{[2]}$.

It is now clear that only about $40 \%$ of patients with heartburn and/or regurgitation have visible distal esophageal mucosal breaks caused by gastroesophageal reflux $^{[3,4]}$. The remaining approximately $60 \%$ suffer from non-erosive reflux disease (NERD) or, according with the Montreal criteria, a typical reflux syndrome ${ }^{[2]}$, i.e. the presence of heartburn and/or regurgitation without esophageal injury.

This negative etiologic definition is not satisfactory: it has been suggested that this may lead to a rather heterogeneous group of patients, including both patients with and without pathological esophageal acid exposure ${ }^{[5]}$. Thus, subcategorization of NERD relies primarily on the results of $24-\mathrm{h}$ esophageal $\mathrm{pH}$ monitoring. Patients with GER symptoms and abnormal esophageal acid exposure during 24-h esophageal $\mathrm{pH}$ monitoring can be classified as NERD; additionally, even patients with a normal esophageal acid exposure but a positive symptom-reflux association may be defined as NERD. The remainder patient may be defined as 
having "functional heartburn"[5]. Recently, the Rome III Committee added that functional heartburn patients also have to demonstrate a negative response to standard course of proton pump inhibitor (PPI) treatment ${ }^{[6]}$.

Since these definitions appear to be useful only at a research setting, and not at a primary care level, in this review we will describe the epidemiology and natural history of NERD patients solely defined on the basis of their symptoms and the absence of endoscopic injury.

\section{EPIDEMIOLOGY}

By far, the best study available up to now is the Kalixanda study ${ }^{[3]}$. The aim of this study was to estimate the prevalence of, and to identify risk factors for gastroesophageal reflux symptoms and esophagitis in the adult population of two Swedish municipalities, Kalix and Haparanda ("the Kalixanda study"), with roughly 30000 inhabitants, chosen because the distribution of age and gender in this area was similar to the national average in Sweden. In the two communities, upper endoscopies were provided by both primary and secondary care physicians and by two endoscopy units involved in the study. By using the computerized Swedish national population register, consisting of all citizens in order of date of birth, the adult population living in the two municipalities was identified and defined as the target population $(n=21610)$. Subsequently, a systematic sample (every seventh) of the target population (13.9\% of the target population) was enrolled as the study population $(n=3000)$, and one-third of them were submitted to an esophagogastroduodenoscopy (EGD) on a voluntary basis, and this formed the study population, i.e. 1000 individuals in random order, representing $4.6 \%$ of the target population. The primary symptom analysis in this study was based on the presence of troublesome heartburn and/or acid regurgitation over the past 3 mo.

Four hundred subjects $(40 \%, \mathrm{CI}=37.0-43.0)$ reported at the time of the EGD visit that they had been bothered by troublesome heartburn and/or acid regurgitation over the past 3 mo. There was no statistically significant difference in prevalence between the sexes, except in the oldest age group, where women had more symptoms $(P<0.01)$.

Weekly symptoms were reported by 200 (20\%, $\mathrm{CI}=17.5-22.5$, mean age $52.4,45 \% \mathrm{M})$ and daily symptoms by 59 individuals $(5.9 \%$, CI $=4.4-7.4$, mean age $52.8,44.1 \% \mathrm{M})$. There was no statistically significant difference in age or gender between these two groups. Erosive esophagitis (EE) was found in 155 subjects $(15.5 \%$, CI $=13.2-17.7)$ with a mean age of 52.6 years and was most prevalent in men $(22 \%)$ especially in the youngest age group $(32 \%)$, and most often mild esophagitis (L-A grade A or B in $95.5 \%$ of cases) was diagnosed. The esophagus was macroscopically normal in 769 subjects $(76.9 \%, \mathrm{CI}=74.3-79.5)$ in the EGD study sample. These subjects had a mean age of 53.5 years and 340 of them (44.1\%) were men. This group also includes 123 individuals who had a hiatus hernia as the only finding. Overall, a hiatus hernia was observed in 239 individuals $(23.9 \%, \mathrm{CI}=21.2-26.5)$ with a mean age of 55.6 years, $54.4 \%$ being men. Thus, in this study, $40 \%$ of subjects reported typical GER symptoms during the last $3 \mathrm{mo}$ (half of them on a weekly basis), and of these $15.5 \%$ had esophagitis whereas $76.9 \%$ had absence of esophagitis (NERD) at upper endoscopy. Globally, about $10 \%$ of the study population had erosive esophagitis $(n=98)$, whereas almost $27 \%$ of the sample had typical GER symptoms but no esophagitis $(n=271)$; if only cases with weekly symptoms were considered, the rate cuts down to $12.5 \%(n=125)$.

In a preliminary report of an Italian endoscopic study, the Loiano-Monghidoro project, conducted on 892 adult subjects belonging to the general population, the prevalence of esophagitis was $8.2 \%$, and $24.8 \%$ of those had no symptoms ${ }^{[4]}$. The prevalence of at least weekly heartburn in the same population was $21.5 \%$.

Therefore, from these two population studies, we can estimate that in Europe at least one tenth of the general population has at least weekly heartburn.

\section{NATURAL HISTORY}

Evaluating the natural history of NERD is useful for a number of reasons ${ }^{[7]}$, this knowledge may help (1) to discern the percentage of the population that will progress from non-erosive to erosive disease and possibly to its complications, such as stricture, Barrett's oesophagus, and esophageal adenocarcinoma, or from exclusively esophageal to supraesophageal manifestations, (2) to define, assess, and validate productivity of risk factors for such complicated forms of the disease, (3) to determine if medical or other therapies are able to positively modify the natural course of the disease, and (4) to determine the need for maintenance therapy to prevent complications and persistent symptoms in such patients.

Until recently, patients with NERD were considered to suffer from a milder disease ${ }^{[8]}$, i.e. requiring less intensive/prolonged treatment and possibly characterized by a better long-term prognosis. This concept was subsequently proven to be incorrect, since the impairment in disease-related quality of life (HRQoL), for example, appears to be similar in GERD patients with or without endoscopic esophagitis and is related in both instances to symptom severity ${ }^{[9]}$. Also, the symptomatic acute response to PPI drugs in patients with or without endoscopic mucosal damage seems not to be different, and in fact might be worse in NERD ${ }^{[10,11]}$. Finally, after discontinuation of acute treatment, symptomatic relapse within 6 months appears to affect a similarly high proportion of both GERD groups ${ }^{[12]}$.

We reported one of the first natural history studies of symptomatic GERD patients without endoscopic esophagitis but with a pathological esophageal $\mathrm{pH}$ metry ${ }^{[13]}$. In that study we showed that 5 of 33 such patients treated with antacids or prokinetic agents developed endoscopic esophagitis within $6 \mathrm{mo}$, and that the extent of esophageal acid exposure at entry was not 
predictive for this complication. In a subsequent study ${ }^{[14]}$, we extended the observation of the original patient group up to a median duration of 10 years. The first interesting observation regarding this patient sample is that almost all patients that we were able to trace $(28 / 29)$ are affected by GERD symptoms when anti-secretory drugs are discontinued, and therefore the majority $(75 \%)$ were on such therapy due to GERD symptoms. Secondly, a very high proportion $(89 \%)$ of our patients in whom repeat endoscopy was performed $(n=18)$ showed an erosive esophagitis. Thus, a considerable proportion of the original patient cohort indeed showed a progression from non-erosive to erosive disease.

Schindlbeck et $a l^{[15]}$, in a study investigating the fate of GERD patients with and without esophagitis, reported on 16 patients with $\mathrm{pH}$-documented GERD and no esophagitis 3 years after the diagnosis. During this period, four patients (25\%) developed reflux esophagitis, while the majority of the patient population, which also included patients with esophagitis at entry, was still taking medications on a daily basis because of their GERD symptoms. Symptoms were rated to be equal or worse than at entry by $70 \%$ of patients in the absence of treatment.

In a Finnish study, 57 consecutive referrals with symptoms of GERD were treated by modification of lifestyle/antacids ${ }^{[16]}$. Initial assessment included endoscopy and esophageal $\mathrm{pH}$ recording, and patients were then followed up for a median of 19.5 years. Of the 30 patients with no evidence of erosive esophagitis at presentation, five $(17 \%)$ developed grade 1 esophagitis according to Savary-Miller classification. In the study by McDougall et a ${ }^{17]}, 71 \%$ of the 17 patients with a pH-metry documented NERD complained of frequent heartburn 3 to 4.5 years after initial diagnosis, $59 \%$ were on daily acid suppressive therapy, and $24 \%$ of those patients who had repeat endoscopy developed esophagitis. Again, a progression from non-erosive to erosive GERD was observed, at least in a proportion of patients.

More recently, we have performed a study on patients with typical GERD symptoms presenting to our laboratory to undergo 24-h esophageal pH-monitoring. We have analyzed patients $(n=35)$ with a pathological investigation, defined as a $24-\mathrm{h} \%$ of GER exceeding $5.0 \%$ of the total recording time, and with a negative upper GI endoscopy. These NERD patients have been interviewed by mean of a structured questionnaire on average three years after the initial diagnosis, in order to assess the presence and severity of GERD symptoms, the therapy (if any) received during this period of follow-up, and the results of any subsequent endoscopic examination performed.

The results of this retrospective survey show that $14 \%$ of those NERD patients who underwent repeat endoscopy developed erosive esophagitis during the 3-year follow-up, despite the fact that almost all of them received effective symptomatic treatment, i.e. H2-RA or PPI therapy ${ }^{[18]}$.

Finally, in a recent multicenter trial ${ }^{[19]}$ conducted on 588 patients with NERD and assessing the effectiveness of continuous $v$ s on demand PPI maintenance therapy, it was observed that a proportion as high as $5 \%$ of patients treated "on-demand" developed erosive changes within 6 mo of study, as compared with $0 \%$ in the continuous treatment arm.

A study has been conducted in a cohort of 3894 patients with predominant heartburn, with or without esophagitis, (1717 NERD, 1512 Los Angeles grade A/B and 278 LA grade C/D, and 387 had Barrett's esophagus) under routine clinical care in Germany, Austria, and Switzerland (ProGERD study) ${ }^{[20]}$. After initial treatment with esomeprazole, they were followed up for two years, regardless of their response. Medical therapy or endoscopy was initiated at the discretion of their primary care physician, in line with routine care. At two years, endoscopy with biopsy was performed according to the protocol. The results were as follows: $25 \%$ of patients who had NERD at baseline progressed to LA A/B and $0.6 \%$ to LA C/D. At 2 years, $22 \%$ of patients had been off medication for at least 3 mo. The conclusions of the authors were that GERD does not seem to be a categorical disease. Progression and regression (the latter likely due to therapy) between grades was observed in this large cohort of patients under routine clinical care.

Another recent study has examined the possible progression in 47 subjects with symptomatic GERD without endoscopic evidence of esophagitis, out of a group of 497 patients undergoing upper GI endoscopy for various reasons ${ }^{[21]}$; all those patients $(47+450)$ were endoscopically assessed annually for 5 years. Esophagitis developed in $36.2 \%$ of patients with NERD, as compared with $11.3 \%$ in the control group, with a hazard ratio of developing esophagitis in the former group of 3.07. The authors concluded that the condition of symptomatic GERD carries a high risk of developing esophagitis, which increases steadily with time and was more frequent in those NERD patients with hiatus hernia, who smoke and drink alcohol, and who are without $H$ pylori infection ${ }^{[21]}$.

All these studies indicate that some patients with NERD may indeed develop erosive disease, at an approximate rate of about $10 \%$ per year. If this rate remains stable with time, a substantial proportion of patients with NERD may develop ERD within 10 years, which is a rate close to what we observed in our 10-year follow-up study of NERD patients ${ }^{[14]}$.

These conclusions are in accordance with results of a recently published systematic review of 22 publications on the endoscopic assessment of erosive or non-erosive GERD over periods larger than 12 months $^{[22]}$. In this review, authors conclude that the observed progression rate from NERD to ERD ranges in the literature from $0 \%$ to $30 \%$. The variability may be related to the duration of follow-up and other factors as $H$ pylori infection.

\section{CONCLUSION}

NERD is a heterogeneous condition, presently defined on the basis of the presence of typical GERD symptoms and the absence of esophageal damage as 
judged by upper endoscopy. This definition is for various reasons unsatisfactory. The prevalence of at least weekly heartburn in the general population in Europe can be estimated to range from $10 \%$ to $20 \%$.

A consistent proportion of this group will develop an erosive esophagitis (progression), even under routine therapeutic care, with a rate probably around $10 \%$ per year within a 10-year frame.

\section{REFERENCES}

1 Vakil N, van Zanten SV, Kahrilas P, Dent J, Jones R. The Montreal definition and classification of gastroesophageal reflux disease: a global evidence-based consensus. Am J Gastroenterol 2006; 101: 1900-1920; quiz 1943

2 Dent J, El-Serag HB, Wallander MA, Johansson S. Epidemiology of gastro-oesophageal reflux disease: a systematic review. Gut 2005; 54: 710-717

3 Ronkainen J, Aro P, Storskrubb T, Johansson SE, Lind T, Bolling-Sternevald E, Graffner H, Vieth M, Stolte M, Engstrand L, Talley NJ, Agreus L. High prevalence of gastroesophageal reflux symptoms and esophagitis with or without symptoms in the general adult Swedish population: a Kalixanda study report. Scand J Gastroenterol 2005; 40: 275-285

4 Zagari RM, Fuccio L, Wallander MA, Johansson S, Fiocca R, Casanova S, Farahmand BY, Winchester CC, Roda E, Bazzoli F. Gastro-oesophageal reflux symptoms, oesophagitis and Barrett's oesophagus in the general population: LoianoMonghidoro study. Gut 2008; 57: 1354-1359

5 Tack J, Fass R. Review article: approaches to endoscopicnegative reflux disease: part of the GERD spectrum or a unique acid-related disorder? Aliment Pharmacol Ther 2004; 19 Suppl 1: 28-34

6 Galmiche JP, Clouse RE, Balint A, Cook IJ, Kahrilas PJ, Paterson WG, Smout AJ. Functional esophageal disorders. Gastroenterology 2006; 130: 1459-1465

7 Locke GR 3rd. Natural history of nonerosive reflux disease. Is all gastroesophageal reflux disease the same? What is the evidence? Gastroenterol Clin North Am 2002; 31: S59-S66

8 Quigley EM, DiBaise JK. Non-erosive reflux disease: the real problem in gastro-oesophageal reflux disease. Dig Liver Dis 2001; 33: 523-527

9 Glise $\mathbf{H}$, Hallerback B, Wiklund I. Quality of life: a reflection of symptoms and concerns. Scand J Gastroenterol Suppl 1996; 221: $14-17$

10 Smout AJPM. Endoscopy-negative acid reflux disease.
Aliment Pharmacol Ther 1997; 11 Suppl 2: 81-85

11 Fass R, Fennerty MB, Vakil N. Nonerosive reflux diseasecurrent concepts and dilemmas. Am J Gastroenterol 2001; 96: 303-314

12 Carlsson R, Dent J, Watts R, Riley S, Sheikh R, Hatlebakk J, Haug $K$, de Groot $O$, van Oudvorst A, Dalvag A, Junghard $\mathrm{O}$, Wiklund I. Gastro-oesophageal reflux disease in primary care: an international study of different treatment strategies with omeprazole. Eur J Gastroenterol Hepatol 1998; 10: 119-124

13 Pace F, Santalucia F, Bianchi Porro G. Natural history of gastro-oesophageal reflux disease without oesophagitis. Gut 1991; 32: 845-848

14 Pace F, Bollani S, Molteni P, Bianchi Porro G. Natural history of gastro-oesophageal reflux disease without oesophagitis (NERD)--a reappraisal 10 years on. Dig Liver Dis 2004; 36: 111-115

15 Schindlbeck NE, Klauser AG, Berghammer G, Londong W, Mueller-Lissner SA. Three year follow up of patients with gastrooesophageal reflux disease. Gut 1992; 33: 1016-1019

16 Isolauri J, Luostarinen M, Isolauri E, Reinikainen P, Viljakka M, Keyrilainen O. Natural course of gastroesophageal reflux disease: $17-22$ year follow-up of 60 patients. Am J Gastroenterol 1997; 92: 37-41

17 McDougall NI, Johnston BT, Collins JS, McFarland RJ, Love $\mathrm{AH}$. Three- to 4.5-year prospective study of prognostic indicators in gastro-oesophageal reflux disease. Scand J Gastroenterol 1998; 33: 1016-1022

18 Pace F, Pallotta S, Molteni P, Zentilin P, Russo L, Savarino V, Bianchi Porro G, Grossi E, Cuomo R. Natural history of NERD in 3 Italian tertiary referral centres after 5 years of follow up. Gut 2006; 55 suppl: A62

19 Bayerdörffer E, Sipponen P, Bigard M, Weiss W, Mearin F, Rodrigo L, Dominguez-Munoz J, Grundling H, Nauclér E, Svedberg L, Keeling N, Eklund S. Esomeprazole $20 \mathrm{mg}$ continous versus on demand treatment of patients with endoscopy-negative reflux disease (ENRD). Gut 2004; 53 (Suppl 4): A106

20 Labenz J, Nocon M, Lind T, Leodolter A, Jaspersen D, Meyer-Sabellek W, Stolte M, Vieth M, Willich SN, Malfertheiner P. Prospective Follow-Up data from the ProGERD Study Suggest that GERD Is Not a categorial disease. Am J Gastroenterol 2006; 101: 2457-2462

21 Kawanishi M. Will symptomatic gastroesophageal reflux disease develop into reflux esophagitis? J Gastroenterol 2006; 41: $440-443$

22 Fullard M, Kang JY, Neild P, Poullis A, Maxwell JD. Systematic review: does gastrooesophageal reflux disease progress? Aliment Pharmacol Ther 2006; 24: 33-45

S- Editor Li DL L- Editor Mihm S E- Editor Yin DH 